\title{
Research on the Current Situation of Rural E-Commerce in the Age of "Internet+" and Its Countermeasures_— Taking Jiangxi County as an Example
}

\author{
Peng Xinping, Zhang Xiumei \\ Pingxiang University, Pingxiang, Jiangxi, 337000
}

Keywords: Rural E-commerce, Countermeasures, Current Situation

\begin{abstract}
Through in-depth investigation and research on rural e-commerce in Jiangxi counties, the problems in the development of rural e-commerce in the province have been discovered, and an in-depth analysis of these issues is conducted. Finally, the paper puts forward the development countermeasures for rural e-commerce in Jiangxi counties, vigorously accelerating the development of rural e-commerce in the province, hoping to provide a good theoretical support and reference for the development of rural e-commerce in the province, and promote the rapid economic and social development of the province.
\end{abstract}

\section{The status of e-commerce development in Jiangxi County}

(1) E-commerce into rural comprehensive demonstration counties, demonstration bases, and model enterprises.

The Provincial Department of Commerce conducts annual assessments of Jiangxi's e-commerce into rural demonstration counties, evaluation of Jiangxi's e-commerce demonstration bases and demonstration companies. In 2014, seven counties such as Ningdu County were rated as national e-commerce rural demonstration counties. In 2015, 15 counties such as Ji County were selected as national e-commerce rural demonstration counties. In 2016, seven counties such as Lichuan County were selected as national e-commerce rural demonstration counties. In 2017, 10 counties such as Le'an County were rated as national e-commerce into rural demonstration counties, which accelerated the popularization and application and promotion of e-commerce, and further led and driven the development of rural e-commerce.

(2) Relying on national policies, vigorously developing rural e-commerce.

Some county-level agricultural electricity suppliers have rapidly emerged, characteristic agricultural products, industrial products, and handicrafts have begun to take shape, and they have actively developed tourism e-commerce. Some counties have established e-commerce industrial parks or e-business startup incubators or e-commerce public service centers.

(3) The penetration of e-commerce from cities to urban and rural areas and the rise of rural online shopping.

Mobile e-commerce has become an important choice for Internet users in our province. $\mathrm{O} 2 \mathrm{O}$ and cross-border e-commerce have developed rapidly. Some counties actively carried out e-commerce knowledge training and established some township and village e-commerce service stations.

(4) Logistics has been further developed.

All counties and regions have basically formed a local logistics distribution system consisting mainly of postal services and various types of express delivery companies, which can basically reach each township. Some counties have taken the lead in integrating all types of private express delivery companies, and established logistics distribution centers and storage centers.

\section{The Problems of rural e-commerce in Jiangxi county}

(1) The overall environment for the development of county-level rural e-commerce needs to be optimized and improved.

Among the existing network operators, except for a small number of enterprises that have entered the e-commerce industry park as e-commerce companies, a large part of them are 
individuals or families, and most of them are part-time and do not have e-commerce industry parks. For reasons of cost and convenience, most network operators choose residential areas as their storage and office space. The information infrastructure of these facilities is incomplete, the surrounding facilities are also not perfect, and the communication and exchange atmosphere between network operators is not strong. There are still not many e-commerce professional service agencies in the counties.

(2) The double loss of advanced concepts and high-end talents affecting the development of county-level e-commerce.

In the era of network economy, major changes have taken place in the business environment and business model. The development of an enterprise requires entrepreneurial ideas to advance with the times. The concept of development of traditional enterprises and rural consumers still need to be further transformed. The strategic understanding of e-commerce needs to be strengthened, and companies lack the high-end e-commerce talents.

(3) The operating mode of county-level e-commerce rural service stations remains to be explored.

At present, county leaders support and train shop owners and promotions of e-commerce rural service stations through e-commerce service organizations such as Alibaba, Jingdong, and postal services. The e-commerce rural service stations provide a wide range of products, and help farmers to buy more online shopping items each month. However, the main focus is still on "industrial products going to the countryside". To really achieve "agricultural products into the city", it is necessary to further accelerate the online operation of rural service stations. At the same time, the distribution of e-commerce rural service stations in some counties is insufficient and not reasonable.

(4) County logistics cooperation needs to be optimized.

Because of the county area is geographically dispersed, the main logistics companies are mainly concentrated in county and district e-commerce incubator parks. According to the support policies of local governments, the prices of parcels issued from incubator parks are relatively cheap. The service stations of some logistics enterprises in towns and townships are relatively far away because they are far away from the county and have poor cooperation between them. Therefore, logistics costs are relatively high. The parcels sent from village Taobao service stations in rural areas are not eligible for express delivery prices in county incubator parks. This has caused great obstacles to the entry of agricultural products into towns. Therefore, the collaboration between villages and township logistics enterprises needs to be optimized.5. The offline support system needs to be further established.

(5) The offline support system needs to be further established.

The development of e-commerce requires strong offline support, branding, design, and dissemination. In these areas, counties are still relatively weak.

(6) The network operator brand needs further development.

At present, the county's brands of products sold through e-commerce are still scattered. Some agricultural products have short shelf life, agricultural product packaging issues, and agricultural product transportation issues. Agricultural products are characterized by strong regionality, strong seasonality, low degree of standardization of products, dispersive producers, and low quality, and have not yet formed an online merchant brand.

\section{The Rural E-Commerce Development Countermeasures in Jiangxi county}

\subsection{Speed up the development and cultivation of e-commerce market players}

1) Accelerate the development of traditional businesses to develop e-commerce. Supporting traditional enterprises to establish e-commerce websites or use third-party e-commerce platforms to conduct online direct marketing services. Supporting commercial and commercial circulation enterprises through online and offline integration, and establish $\mathrm{O} 2 \mathrm{O}$ offline exhibition hall, promote the integration of traditional businesses and e-commerce, and expand sales channels. Focusing on tourism resources such as ecotourism, red tourism, and patina tourism, we will develop 
e-commerce businesses integrating catering, accommodation, and scenic spot tickets.

2) Speed up the development of professional e-commerce companies. We will give full play to the leading role of leading e-commerce companies in each county, accelerating the development of local e-commerce companies with growth potential, actively nurturing e-commerce companies with strong competitiveness, and further increasing market competitiveness.

3) Actively introduce e-commerce companies. Actively introduce powerful e-commerce enterprises to promote the development of local e-commerce enterprises and lead the development of e-commerce industries in all counties. Actively explore cooperation with large-scale e-commerce companies, absorb advanced experience, and optimize the geographical environment.

4) Actively develop the online business brand. Strengthen the cooperation with well-known e-commerce companies, and carry out strategic cooperation with well-known e-commerce platform companies such as Taobao, Tmall, Alibaba, Jingdong, Yihaodian, Meituan, and Ctrip, expand sales channels, and increase the visibility of county-level specialty products; Encourage and guide local leading enterprises and actively open flagship stores, specialty stores and franchise stores on third-party platforms to cultivate online marketing brands.

5) Accelerate the cultivation of individual network operators. Actively nurture and create a county-level e-commerce entrepreneurial atmosphere, encourage college students, farmers, and individuals to conduct online business through e-commerce, encourage e-commerce entrepreneurs to return to their hometowns, and continuously expand their network of business teams. Intensify e-business entrepreneurship training and policy guidance, publicize and promote the successful experience of the development of network operators, and create a good atmosphere for e-commerce. In addition, focusing on university graduates, returning entrepreneurs, individual industrial and commercial households, a group of rural e-commerce entrepreneurial leaders will be cultivated and the network of farmers-related networks will continue to grow. The first is to encourage individuals to actively participate in online entrepreneurship. Initial network entrepreneurs can apply for admission to all levels of network startup parks and startup incubators. The second is to vigorously promote the "store + shop" entrepreneurial model, and actively guide individual industrial and commercial households to use the network to carry out the second venture. The third is to promote traditional enterprises to launch online sales, self-built online trading platforms or use third-party e-commerce platforms. The fourth is to excavate and promote a number of successful cases of network operators, and vigorously promote their successful experience.

6) Support conditional groups to start businesses with e-commerce. Actively guide rural professional cooperatives, agricultural product bases, brokers, and farms to expand their network sales business. Actively nurture and guide e-commerce service companies to serve the rural market and provide them with professional services such as website construction, online store decoration, online shop promotion, online store operations, and warehousing logistics, and bring more rural enterprises to actively develop rural e-commerce. Adopt the "training + incubation + cultivation" model, give full play to the guiding role of the relevant departments of industry, youth and women, and carry out e-commerce knowledge training for college students, returning entrepreneurial youth and self-employed individuals. Relying on e-commerce, the company opened stores in famous e-commerce platforms such as Tmall and Jingdong to drive the development of county network operators.

7) Build rural e-commerce gathering areas. Learn and use the development model of "Taobao Village" to actively develop e-commerce applications in villages and towns with basic conditions. Efforts should be made to guide local villagers in e-commerce ventures, increase e-commerce training, and actively provide warehousing logistics, product quality control, e-commerce services and other public ancillary services. Promote the gathering and development of network operators in rural areas.

8) Expand e-commerce consumer groups. Use various training and learning opportunities to increase e-commerce awareness among residents and increase online consumer enthusiasm. Relying on the service function of the integrated e-commerce industry park, we will give full play to the "park” agglomeration effect and guide everyone to actively participate in e-commerce. 


\subsection{Efforts to enhance the universal application of e-commerce}

Accelerate the pace of promoting e-commerce applications, make large stocks and expand incrementally. Accelerate the deep integration of key industries such as e-commerce and manufacturing, traditional trade and business, Governments, enterprises, and communities should apply e-commerce in depth and vigorously increase the level of e-commerce applications.

1) Cultivate leading enterprises and lead the development of e-commerce. The government should take the enterprise as the main carrier of e-commerce, through policy guidance, the government should nurture a group of industry-leading e-commerce leading enterprises and cross-border e-commerce leading enterprises, and give full play to their leading role. Encourage qualified leading enterprises to actively build an industry e-commerce platform to lead and drive the development of e-commerce.

2) Cultivate rural e-commerce model enterprises. Encourage small and medium-sized enterprises, farmers' professional cooperatives, rural entrepreneurship youths, university students village officials, and veterans to launch rural e-commerce activities. Guide enterprises to focus on the development, cultivation and brand building of online marketing agricultural products, and cultivate a number of rural e-commerce model enterprises.

3) Promote the use of e-commerce by small, medium and micro enterprises. Strengthen the e-commerce promotion and training for small, medium and micro enterprises, and encourage small and medium-sized enterprises to use third-party e-commerce platforms to conduct online purchases and network marketing activities. Cultivate a group of commercial and commercial circulation enterprises with annual sales of over 10 million yuan, and expand the application scale of B2C e-commerce.

4) Develop foreign trade cross-border e-commerce. Encourage and guide traditional enterprises engaged in foreign trade business to actively use Alibaba International Station, China Manufacturing Network, Dunhuang Net and other platforms to develop foreign trade cross-border B2B e-commerce; Encourage the development of cross-border B2C e-commerce with foreign exchange, eBay and other platforms. Accelerate the docking of enterprises holding cross-border payment licenses inside and outside the province to serve the city's cross-border e-commerce business; Actively introduce and focus on cultivating a batch of foreign trade e-commerce service companies to provide cross-border e-commerce for SMEs to provide supporting services and continuously improve the level of e-commerce applications in the foreign trade industry.

5) Guide the development of e-commerce in agricultural products. Based on the characteristics of agro-forestry, guide agricultural enterprises, farmer cooperatives, and farmers to open online stores on platforms such as Taobao and Tmall. Support in-depth cooperation among leading agricultural enterprises, farmer cooperatives and professional e-commerce companies to increase the penetration of e-commerce applications in agriculture.

6) Encourage travel e-commerce. Relying on the rich tourism resources in the region, integrate county-level agricultural products, specialty products and other resources, and use e-commerce tools to deeply promote. Make full use of travel websites like Tongcheng, Ctrip and Letu to promote tourism products, gradually develop e-commerce in tourism, and increase the visibility and influence in the province and even the whole country.

7) Accelerate the application of e-commerce in the field of livelihood. Accelerate the progress of the planning and construction of "Wisdom Pingxiang", utilize e-commerce means to integrate public service resources and actively construct an intuitive, interactive, convenient, standardized, and reliable Pingxiang public information and livelihood service e-commerce platform. Achieve the transformation of the traditional people's livelihood service to the smart city service model and comprehensively improve the public service quality of the people's livelihood. Create "wisdom, efficiency, and convenience" of urban life. Deepening the application of e-government, focusing on the government's information resources, and constantly improving the disclosure of the government's information network. Expand the content and scope of online services and increase the efficiency and capacity of online services. To achieve cross-departmental information resource sharing and improve the efficiency of work and business collaboration among departments. 
8) Expand the application of e-commerce in rural areas. Support e-commerce companies to develop rural markets and expand e-commerce applications.

\subsection{Accelerate the Development of Regional E-Commerce Industrial Parks}

Every county can build a number of e-commerce industrial parks based on the existing industrial park resources. And e-commerce industrial parks can be used as the main platforms and main positions for the development of the e-commerce industry, and the corresponding e-commerce supporting services can be improved. Encourage and attract e-commerce companies to enter the park and form an e-commerce park integrating office, warehousing, display, incubation, training, reception, leisure and entertainment. We will vigorously support the construction of e-commerce industrial parks, integrate resource advantages, and give certain policy support to enterprises that have settled in the park.

1) Accelerate the construction of an e-commerce core park. Speed up the construction of an e-commerce integrated industrial park. Accelerate the speed of the project, making it become the home base for small and medium-sized businesses and youth online entrepreneurship. Speed up the layout of e-commerce integrated industrial park projects. According to the criteria of "high starting point, high standards, and high demands", key resources and elements such as core data, core platforms, and professional services of e-commerce are planned to create a strategic highland for e-commerce. Through policy guidance, financial support, and atmosphere creation, various elements of e-commerce development will be integrated to promote mutual influence and interaction among various elements, and to form agglomeration development effects. Maximize the potential of regional e-commerce and lead the development of regional e-commerce.

2) Speed up the construction of e-commerce agglomerations. Guided by the regional e-commerce strategic planning, we will speed up the construction of e-commerce clusters and strengthen the correlation between e-commerce clusters and e-commerce core campuses and e-commerce service centers. Achieve the rational distribution of various functions of regional e-commerce among various types of carriers and create a harmonious, unified and efficient regional e-commerce space structure.

3) Speed up the construction of township electricity supplier industry business park. Each county shall actively build a pattern of development of the "electricity business industry clustering in one county and multiple parks", improve supporting services and functions, increase the occupancy rate, and achieve the sharing of information resources. Each township exerts its local characteristics and advantages, establishes township electricity supplier industrial parks, and guides and promotes the growth of e-commerce enterprises.

\subsection{Building a Regionalized and Characteristic E-commerce Trading System}

1) Speed up the construction of a local e-commerce platform. Focus on accelerating the construction of e-commerce platform in the same city, focusing on supporting the extension and development of large-scale professional e-commerce platforms integrating information exchange, payment, and information services.

2) Cultivate and develop e-commerce platforms in traditional industries. Focus on supporting large local leading enterprises to gradually open e-commerce platforms to the society, integrate product and service resources, and transform them into third-party industry e-commerce platforms.

3) Strengthen cooperation with third-party e-commerce platforms. Encourage companies to use the existing e-commerce platform for online sales. Enterprises can make full use of Taobao and other C2C platforms, domestic B2B platforms such as Alibaba Domestic Station and HC Network, and B2C e-commerce platforms such as Tmall, Jingdong, Dangdang, Suning, Vipshop, and Amazon to develop online sales. Enterprises can establish strategic partnerships with e-commerce giants such as Alibaba and JD.com to promote Ali and Jingdong to the region. Enterprises can combine the industrial characteristics of counties and integrate product resources. Established "Featured Pavilion" in Ali "Taobao Characteristic Pavilion" and established "Specialty Pavilion" in Jingdong Mall. Enterprises can also set up Alibaba and JD Online offline experience centers locally. Using its mature platform to drive the sales of various county networks, it will help the transformation and 
upgrading of local traditional businesses.

4) Encourage and introduce large-scale e-commerce platform companies from home and abroad to settle in the counties. Encourage and guide large-scale e-commerce platform companies at home and abroad to establish regional headquarters economy in each county and promote the development of county-level e-commerce.

5) Build a tourism e-commerce platform. Open up multimedia portals for government's foreign tourism services and build a tourism e-commerce platform guided by smart tourism. Integrate tourism service resources such as tourist attractions, hotels, travel agencies, specialty products, tourism products, and original ecological cuisine, and establish a resource database of complete tourism elements to support multiple access methods and provide comprehensive services to the public. Realize the promotion of attractions, online booking, and open online information inquiry and transaction functions such as hotels and hotels.

6) Create a multi-platform feature China Pavilion. Selected excellent operators and eco-product brands to build multi-e-commerce platform featured China Pavilions such as Taobao.com, Jingdong, Suning.com, and No.1 shop. Utilize these nation's largest online retail platforms to promote brand promotion of agricultural products. Supports the establishment of an online flagship store relying on well-known platforms such as Tmall, JD.com and Suning.com, and promotes the sales of ecological products by adopting unified marketing methods.

7) Establish a regional $\mathrm{O} 2 \mathrm{O}$ trading enterprise trading platform. Combining the development status of local and regional business enterprises, we encourage traditional trading companies to revitalize physical resources offline, maximize user experience, and enhance their competitiveness.

Enterprises should do a good job in product brand promotion and customer service online and build $\mathrm{O} 2 \mathrm{O}$ stores online. At the same time, they should also strengthen cooperation with community convenience stores and stores.

8) Encourage enterprises to build mobile e-commerce service platforms. Encourage companies to actively carry out WeChat marketing, establish micro-sites, micro-stores, WeChat public platform, increase product promotion and sales.

\subsection{Speed up the construction of e-commerce talent system}

1) Extensively develop rural e-commerce training. Employing e-commerce training to create a good atmosphere for the development of e-commerce, strengthen e-commerce guidance, and guide the people to participate in e-commerce applications. Support and encourage e-commerce training institutions to carry out e-commerce skills training for youths, college students, and business leaders in rural areas to develop e-commerce skills such as online shopping, online shop opening, and online shop promotion, and cultivate e-commerce talents.

2) Vigorously develop network operators. Build an industry communication platform to promote the interaction and cooperation of local network operators. Assisting netizens in connecting with e-commerce platforms and service companies, providing quality services on the Internet and expanding online teams. Support network operators who have close cooperation with large-scale e-commerce platforms at home and abroad, have strong resource integration capabilities and can leverage the advantages of manufacturing companies, and build large-scale network operators with national and international influence. Strengthen exchanges and cooperation with large-scale e-commerce platform companies such as Alibaba and HC Network, and encourage leading global and domestic network operators to conduct online trade projects in this region, and give priority to the introduction of online trade projects that can take advantage of the region's manufacturing, manufacturing, and trade circulation industries and expand the team of network operators.

3) Increase talent introduction and cultivation. We will intensify the introduction of e-commerce talents, improve the incentive measures for e-commerce talents, introduce high-end talents and compound talents suitable for the development of e-commerce in the region through multiple channels, and build professional e-commerce technology and management talents. On the one hand, enterprises are encouraged to attract high-level e-commerce management personnel, high-end operational talents, and core technical talents to work and start their own businesses. On the other 
hand, it actively guides Jiangxi merchants to return, and encourages e-commerce practitioners to return to their hometowns for employment and entrepreneurship; Third, cultivating e-commerce talents from colleges and universities and educating e-commerce talents on their own; Fourth, vigorously develop the e-commerce outsourcing business, encourage the establishment and introduction of professional e-commerce outsourcing service companies, undertake e-commerce projects and provide services for other companies.

4) Accelerate the establishment of a long-term training mechanism for e-commerce. Actively carry out the village Taotao popularization classes, e-commerce entrepreneurship primary classes, e-commerce venture operation classes, e-commerce entrepreneurial operation classes, corporate e-commerce president classes, government agencies, e-commerce popularization classes, e-commerce summit forum.

5) Accelerate the construction of multi-level e-commerce talent echelon. External introduction of high-end e-commerce talents, internal training of skilled support personnel. For some special talents that are urgently needed and difficult to recruit for a short period of time, in accordance with the purpose of "do not ask for everything, but for their own use", encourage and encourage high-end talents. Encourage high-end talents to participate in rural e-commerce construction in various forms.

\subsection{Improve rural e-commerce support system}

1) Establish a corporate credit evaluation system. Leading by industry and commerce departments, regulate the operation of rural e-commerce market, and promote the construction of e-commerce enterprise credit evaluation system. Establish trustworthy incentives and dishonesty disciplinary mechanisms to crack down on illegal activities such as counterfeiting and shoddy goods produced and sold in rural areas. Effectively protect the legitimate rights and interests of rural consumers and network operators, and create a good credit environment for the development of e-commerce. We will explore the establishment of an e-commerce credit system, establish a credible e-commerce credit service platform, promote the building of an e-commerce business integrity alliance, and launch the e-commerce company's credit evaluation results publicity.

2) Strengthen the safety supervision and security system. The department of food safety and safety supervision will take the lead to strengthen the supervision of quality and safety in the online sales of agricultural products and establish a traceability system for supply chains. Achieve monitoring records of the whole process of production, warehousing, transportation, and consumption. Form the supervision covering the entire process from the field to the table, ensure that the production of agricultural and sideline products can be traced back. And by the government or industry associations to provide guarantees to improve online consumer confidence and experience.

3) Improve statistical monitoring service system. Use third-party technology to monitor key online merchants and online stores and trengthen e-commerce operation monitoring and data analysis to provide important information for management and decision-making.

4) Build an e-commerce technology support service system. Introduce advanced e-commerce operation service agencies to provide professional support. Seek technical support and teamwork for e-commerce development. Establish an effective talent introduction and reward mechanism, actively create conditions, and develop high-end e-commerce talents, especially mature teams, to create a good business environment and environment for them. Form long-term cooperation relationship with mature e-commerce professional teams, professionally conduct product brand planning, marketing promotion, subject cultivation, and operation guidance.

5) Establish e-commerce investment and financing system. Guided by government funds, combined with bank credit, social investment, and inciting social funds to participate together, support the development of third-party e-commerce platforms, public support systems, key technology applications, and e-commerce clusters.

6) Build e-commerce promotion and promotion system. Intensify e-commerce training and increase the promotion of e-commerce by outdoor advertising, television advertising, and online advertising. Hold e-commerce forums and other exchange meetings. Promote the typical cases of 
e-commerce success and create a good atmosphere for e-commerce startup.

\section{Conclusions}

Continuously crack down on e-commerce barriers in rural areas, speed up the development of rural e-commerce, further promote economic restructuring and industrial upgrading in our province, improve the market competitiveness of enterprises in our province, quickly achieve the rapid economic development of our province, and fully achieve a well-off society.

\section{Acknowledgements}

This paper is grateful for the support of Jiangxi Science and Technology Department's Soft Science Research Plan General Project (20161BBA10027) and Jiangxi Humanities and Social Sciences Research Project (GL161010).

\section{References}

[1] Peng, Xinping. Study on the E-commerce Development in the Rural Areas of Counties[J].2015 2nd international symposium on engineering technology, education and management[J],2015.

[2] Yang Yongbo. Research on the development of rural e-commerce in the era of "Internet" [J]. Journal of Agricultural Economics, 2017(09). 